Check for updates

Cite this: RSC Adv., 2017, 7, 25019

Received 16th February 2017

Accepted 12th April 2017

DOI: 10.1039/c7ra01954h

rsc.li/rsc-advances

\title{
A $\mathrm{Cr}_{2} \mathrm{O}_{3} / \mathrm{MWCNTs}$ composite as a superior electrode material for supercapacitor $\dagger$
}

\author{
Bingwei Chen, ${ }^{\text {ab }}$ Yanfang Wang, ${ }^{\mathrm{b}}$ Chunyang Li, ${ }^{\mathrm{a}} \mathrm{Lijun} \mathrm{Fu},{ }^{\mathrm{a}}$ Xiang Liu, ${ }^{\mathrm{a}}$ Yusong Zhu, ${ }^{\text {a }}$ \\ Lixin Zhang*b and Yuping Wu iD *ab
}

\begin{abstract}
It has been a challenge to achieve a good capacitive performance for $\mathrm{Cr}$-based oxides, and only few studies have been reported on these oxides. Herein, a composite of chromium oxide $\left(\mathrm{Cr}_{2} \mathrm{O}_{3}\right)$ and multi-walled carbon nanotubes (MWCNTs) was prepared by a simple hydrothermal procedure followed by thermal decomposition. The $\mathrm{Cr}_{2} \mathrm{O}_{3}$ nanoparticles were evenly decorated on the surface of MWCNTs. The prepared $\mathrm{Cr}_{2} \mathrm{O}_{3} /$ MWCNTs composite exhibited superior electrochemical performance in a $1 \mathrm{M} \mathrm{KOH}$ electrolyte, i.e., $257 \mathrm{~F} \mathrm{~g}^{-1}$ at the current density of $0.25 \mathrm{~A} \mathrm{~g}^{-1}$, and the capacity fade was only $12 \%$ after 3000 cycles. In addition, the $\mathrm{Cr}_{2} \mathrm{O}_{3} / \mathrm{MWCNTS} / / \mathrm{AC}$ asymmetric capacitor has high energy density (15.2 $\mathrm{W} \mathrm{h} \mathrm{kg}-1$ at $266 \mathrm{~W} \mathrm{~kg}^{-1}$ ). The abovementioned results for the first time indicate the potential application of $\mathrm{Cr}_{2} \mathrm{O}_{3}$ as an electrode material for supercapacitors.
\end{abstract}

\section{Introduction}

Recently, the need of modern society and emerging energy shortage have stimulated untiring research effort into novel, cheap, and eco-friendly energy storage systems. ${ }^{1}$ Lithium-ion batteries $^{2}$ (LIBs) and supercapacitors ${ }^{3,4}$ are two major energy storage devices. Supercapacitors have fast charge-discharge capability, high power density, and excellent cycling stability in comparison with LIBs. ${ }^{5}$

Generally, on the basis of operating principle, supercapacitors can be classified into two types. One is electrical double-layer capacitors (EDLCs), which store energy by accumulating charges at the surface of the electrodes. Carbon materials including activated carbon (AC), carbon aerogel, carbon nanotubes (CNTs), and graphene have been widely applied in EDLCs. These EDLCs have outstanding cycling performance as no chemical reaction occurs in them. ${ }^{6}$ However, major drawbacks of these supercapacitors are their low energy density and specific capacitance. The other is faradaic supercapacitors that store energy through reversible redox reactions. $^{7,8}$

Transition metal oxides (TMO) such as $\mathrm{MnO}_{2},{ }^{8-10} \mathrm{RuO}_{2},{ }^{11}$ $\mathrm{V}_{2} \mathrm{O}_{5},{ }^{12,13} \mathrm{MoO}_{3},{ }^{14,15} \mathrm{Co}_{3} \mathrm{O}_{4},{ }^{16}$ and $\mathrm{NiO}^{17}$ possess a higher pseudocapacitance and energy density compared with carbon

${ }^{a}$ School of Energy Science and Engineering, Institute for Electrochemical Energy Storage, Nanjing Tech University, Nanjing 211816, Jiangsu Province, China. E-mail: wuyp@fudan.edu.cn; Fax:+86-21-55664223

${ }^{b}$ New Energy and Materials Laboratory (NEML), Department of Chemistry, Shanghai Key Laboratory of Molecular Catalysis and Innovative Materials, Fudan University, Shanghai 200433, China

$\dagger$ Electronic supplementary information (ESI) available. See DOI: 10.1039/c7ra01954h materials. In general, use of metal oxides as supercapacitors is limited by their poor conductivity and lower specific surface area (SSA).

CNTs, known for their diverse and promising mechanical and electrical features, have been widely investigated and applied in various energy storage devices. Due to their excellent properties such as suitable pore structure, high SSA, superior conductivity as well as stability, CNTs act as an ideal skeleton for metal oxide nanoparticles to grow. At present, the primary way to grow nanoparticles on CNTs is their surface functionalization by efficient oxidizer to produce hydrophilic groups. These groups can act as nucleation centers for in situ assembling of nanoparticles on the surface of CNTs. The CNTs have been combined with various metal oxides to form composite electrodes. For instance, CNTs could be used as a conducting network to improve the electrochemical reversibility of some oxides, such as $\mathrm{MnO}_{2}$, and enhance their capacitive enhancement. ${ }^{\mathbf{9}, 18}$

As a p-type TMO semiconductor with a wide band gap $\left(E_{\mathrm{g}} \sim\right.$ $3.4 \mathrm{eV}), \mathrm{Cr}_{2} \mathrm{O}_{3}$ is widely applied in optical and electronic devices, catalysts, gas sensors, and colorants due to its high electrical conductivity, special optoelectronic characteristics, as well as high thermal and chemical stability. ${ }^{19} \mathrm{Cr}_{2} \mathrm{O}_{3}$ is cheap and easily available. Therefore, it is a promising candidate for supercapacitor electrode materials. As for the fourth period transition metal elements, it is known that oxides of Ti, V, (Cr), Mn, Fe, Co, and Ni can be utilized as supercapacitors, electrode materials, etc. To date, very few studies have been reported on oxides of $\mathrm{Cr}$, thereby indicating that it is a challenge to achieve a good capacitive performance for Cr-based oxides.

In this study, we successfully synthesized a $\mathrm{Cr}_{2} \mathrm{O}_{3} /$ MWCNTs composite. $\mathrm{Cr}_{2} \mathrm{O}_{3}$ nanoparticles were well-distributed on the 
MWCNTs. In particular, the composite electrode delivered a high specific capacitance of $257 \mathrm{~F} \mathrm{~g}^{-1}$ at the current density of $0.25 \mathrm{~A} \mathrm{~g}^{-1}$. The capacity fade was only $12 \%$ after 3000 cycles, indicating good cyclic stability of the composite. In addition, energy density of the $\mathrm{Cr}_{2} \mathrm{O}_{3} / \mathrm{MWCNTs} / / \mathrm{AC}$ asymmetric capacitor (ASC) could reach up to $15.2 \mathrm{~W} \mathrm{~h} \mathrm{~kg}^{-1}$ at the power density of $266 \mathrm{~W} \mathrm{~kg}^{-1}$. The present study provides an effective strategy to design new materials based on the combination of CNTs and $\mathrm{Cr}_{2} \mathrm{O}_{3}$ for energy storage devices.

\section{Experimental}

\section{Preparation of the composite}

The MWCNTs, 30-50 $\mathrm{nm}$ in diameter, were purchased from Chengdu Organic Chemicals Co. Ltd., Chinese Academy of Science. The AC with a specific surface area of $1600 \mathrm{~m}^{2} \mathrm{~g}^{-1}$ was purchased from Ningde Xinsen Chemicals Co. Ltd. All other chemical reagents used in this study were of analytical grade purity and were purchased from Sinopharm Chemical Reagent Co. Ltd, and used without any purification. The MWCNTs were treated with $6 \mathrm{M} \mathrm{HNO}_{3}$ solution to purify and render hydrophilic groups on the surface., ${ }^{9,20}$ Next, $20 \mathrm{mg}$ acid-treated MWCNTs were immersed in a $0.03 \mathrm{M} \mathrm{Cr}\left(\mathrm{NO}_{3}\right)_{3} \cdot 9 \mathrm{H}_{2} \mathrm{O}$ absolute ethanol solution $(35 \mathrm{~mL})$. Then, the solution was transferred to a Teflon-lined stainless steel autoclave of $40 \mathrm{~mL}$ volume and heated at $180{ }^{\circ} \mathrm{C}$ for $12 \mathrm{~h}$. After filtration and washing with deionization water, the product was dried at $80{ }^{\circ} \mathrm{C}$ overnight. The formed precipitate was finally annealed at $500{ }^{\circ} \mathrm{C}$ for $3 \mathrm{~h}$ under the protection of $\mathrm{N}_{2}$. Moreover, pristine $\mathrm{Cr}_{2} \mathrm{O}_{3}$ nanoparticles were prepared by calcifying $\mathrm{Cr}_{2} \mathrm{O}_{3} / \mathrm{MWCNTs}$ composite at $500{ }^{\circ} \mathrm{C}$ for $2 \mathrm{~h}$ in air.

\section{Characterization}

The structures and morphologies of the materials were analyzed by X-ray diffraction (XRD, Bruker D4), scanning electron microscopy (SEM, Philip XL 300 microscope), transmission electron microscopy (TEM, JEOL JEM-2010), and $\mathrm{N}_{2}$ adsorptiondesorption test (TRISTAR3000, MICROMERITICS). Thermal properties of the composite were investigated by thermogravimetric analysis (TGA, Du-Pont TGA-2950).

\section{Electrochemical tests}

The working electrode was fabricated by mixing the active material (80 wt\%), acetylene black (10 wt\%), and polytetrafluoroethylene (PTFE) (10 wt $\%)$. Then, the mixture was coated on a Ni grid with the active material mass loading of $0.8 \mathrm{mg}$ $\mathrm{cm}^{-2}$. After being dried at $80{ }^{\circ} \mathrm{C}$ overnight, they were used for electrochemical measurements.

The electrochemical measurements were evaluated by cyclic voltammetry (CV) and electrochemical impedance spectroscopy (EIS) using a CHI440B electrochemical working station (Shanghai, China). The galvanostatic charge/discharge (GCD) measurement was conducted using an automatic LAND battery (Wuhan, China). A three-compartment cell was assembled by the abovementioned working electrode, a Ni grid (counter electrode), and a saturated calomel electrode (SCE, reference electrodes). The specific capacitance was calculated according to the following equation:

$$
C_{\mathrm{s}}=\int \frac{I \mathrm{~d} t}{m \mathrm{~d} V}
$$

where $C_{\mathrm{s}}$ is the specific capacitance $\left(\mathrm{F} \mathrm{g}^{-1}\right), I$ is the current (A), $\mathrm{d} t$ is the time (s), $m$ is the mass of the active materials (g), and $\mathrm{d} V$ is the voltage change.

\section{Results and discussion}

\section{Morphology and structure}

The XRD patterns of the $\mathrm{Cr}_{2} \mathrm{O}_{3}$ /MWCNT nanocomposite, virginal $\mathrm{Cr}_{2} \mathrm{O}_{3}$, and MWCNTs are shown in Fig. 1a. The $\mathrm{Cr}_{2} \mathrm{O}_{3} /$ MWCNT nanocomposite shows peaks at around $25^{\circ}, 34^{\circ}, 37^{\circ}$, $42^{\circ}, 51^{\circ}, 55^{\circ}, 64^{\circ}$, and $66^{\circ}$ corresponding to the (012), (104), (110), (113), (204), (116), (214), and (300) crystal planes of $\mathrm{Cr}_{2} \mathrm{O}_{3}$ (JCPDS no. 06-0504), respectively. The peak at around $26^{\circ}$ indicates the existence of MWCNTs. For the $\mathrm{Cr}_{2} \mathrm{O}_{3} / \mathrm{MWCNT}$ composite, the intensity of the (110) plane is obviously stronger than that of the (012) plane as the $\mathrm{Cr}_{2} \mathrm{O}_{3} / \mathrm{MWCNT}$ composite has a crystal orientation along the (110) plane. The (110) plane has more $\mathrm{Cr}$ atoms compared to other planes, which can provide more active sites during the $\mathrm{OH}^{-}$insertion/extraction process (Fig. S1†). Moreover, other impurity peaks were not detected. The content of $\mathrm{Cr}_{2} \mathrm{O}_{3}$ in $\mathrm{Cr}_{2} \mathrm{O}_{3}$ /MWCNTs was
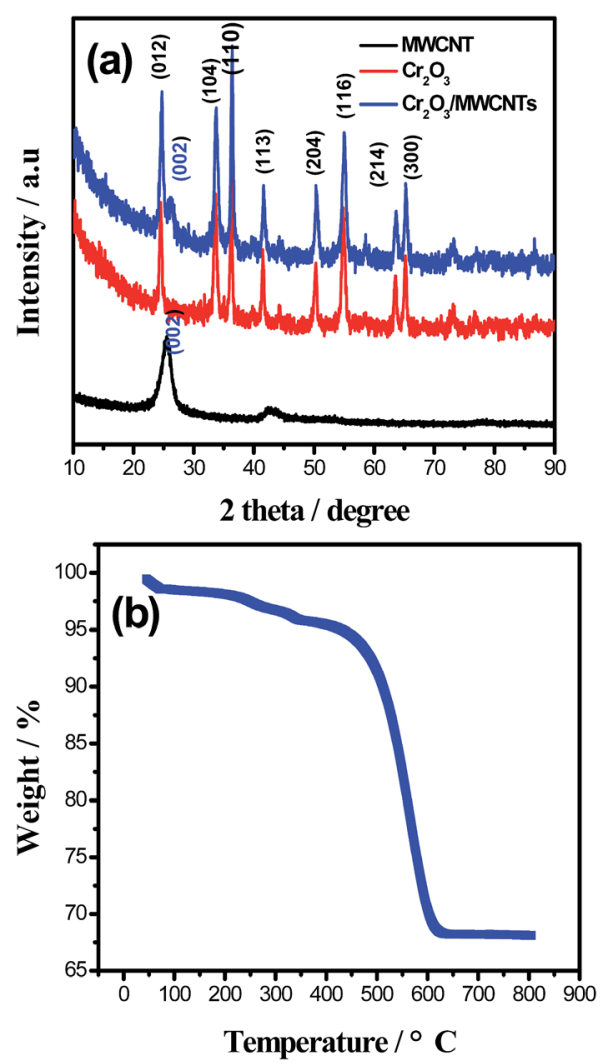

Fig. 1 (a) XRD pattern and (b) TG analysis of the $\mathrm{Cr}_{2} \mathrm{O}_{3} / \mathrm{MWCNT}$ composite. 
accurately calculated by TGA, as shown in Fig. 1b, as $68 \mathrm{wt} \%$ in the composite.

The porosity of $\mathrm{Cr}_{2} \mathrm{O}_{3}$ and $\mathrm{Cr}_{2} \mathrm{O}_{3}$ /MWCNT composite was analyzed by $\mathrm{N}_{2}$ adsorption-desorption test, as shown in Fig. 2a and $\mathrm{b}$, respectively. The relevant parameters including Brunauer-Emmett-Teller (BET) surface area $\left(S_{\mathrm{BET}}\right)$, total pore volume $\left(V_{\text {Tot }}\right)$, and average pore size $\left(D_{\text {av }}\right)$ are listed in Table 1. The $\mathrm{Cr}_{2} \mathrm{O}_{3} /$ MWCNT composite demonstrated a type-IV isotherm, and a small hysteresis loop can be observed at the relative pressure between 0.7 and 0.95 , which implied the presence of mesopores in the surface structure. The $\mathrm{Cr}_{2} \mathrm{O}_{3}$ / MWCNT composite possesses a $S_{\mathrm{BET}}$ of $225 \mathrm{~m}^{2} \mathrm{~g}^{-1}$ and higher $V_{\text {Tot }}$ of $0.741 \mathrm{~cm}^{3} \mathrm{~g}^{-1}$. In general, $S_{\mathrm{BET}}$ is a vital factor influencing the specific capacitance since charges accumulate on the surface of the supercapacitor electrodes and a higher SSA of the electrode usually result in an increased specific capacitance. ${ }^{21}$ According to the Barrett-Joyner-Halenda (BJH) pore size distribution plot, the average pore size of the $\mathrm{Cr}_{2} \mathrm{O}_{3}$ /MWCNT composite was calculated to be $6.67 \mathrm{~nm}$. The increase of the pore size in the mesoporous region indicates improved energy and power outputs of the supercapacitors. ${ }^{22}$

The SEM (Fig. 3a) and TEM (Fig. 3b and c) images of the $\mathrm{Cr}_{2} \mathrm{O}_{3}$ /MWCNT composite show that the $\mathrm{Cr}_{2} \mathrm{O}_{3}$ nanoparticles are evenly decorated on the surface of the MWCNTs. The size of the $\mathrm{Cr}_{2} \mathrm{O}_{3}$ nanoparticles are in the range from 5 to $10 \mathrm{~nm}$. The abovementioned results confirmed the successful synthesis of the $\mathrm{Cr}_{2} \mathrm{O}_{3} / \mathrm{MWCNT}$ composite. In contrast, the virginal $\mathrm{Cr}_{2} \mathrm{O}_{3}$
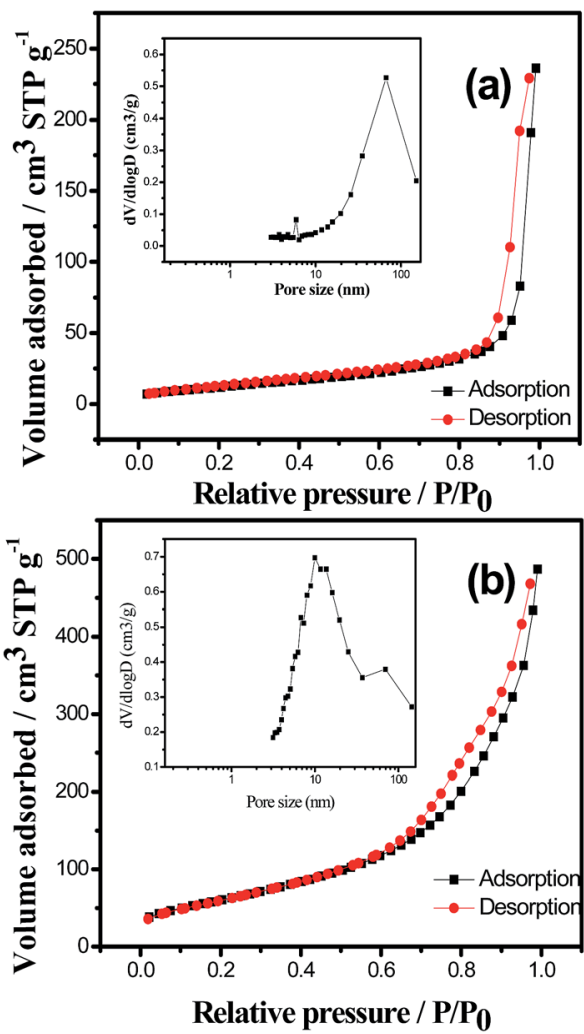

Fig. $2 \mathrm{~N}_{2}$ adsorption-desorption isotherms and pore size distribution (inset) of (a) virginal $\mathrm{Cr}_{2} \mathrm{O}_{3}$ and (b) $\mathrm{Cr}_{2} \mathrm{O}_{3}$ /MWCNT composite.
Table 1 The relevant porosity parameters for virginal $\mathrm{Cr}_{2} \mathrm{O}_{3}$ and its composite

\begin{tabular}{llll}
\hline Sample & $S_{\text {BET }}\left(\mathrm{m}^{2} \mathrm{~g}^{-1}\right)$ & $V_{\text {Tot }}\left(\mathrm{cm}^{3} \mathrm{~g}^{-1}\right)$ & $D_{\mathrm{av}}(\mathrm{nm})$ \\
\hline $\mathrm{Cr}_{2} \mathrm{O}_{3} /$ MWCNTs & 224.9 & 0.741 & 6.76 \\
$\mathrm{Cr}_{2} \mathrm{O}_{3}$ & 45.7 & 0.362 & 5.93 \\
\hline
\end{tabular}

particles were agglomerated (Fig. 3d). Perhaps, the MWCNT framework could distinctly impede the aggregation of the $\mathrm{Cr}_{2} \mathrm{O}_{3}$ nanoparticles during the crystal growth process, resulting in their smaller diameter and better dispersion on the MWCNTs.

The CV curves of the two samples at the scan rate of $10 \mathrm{mV}$ $\mathrm{s}^{-1}$ between -0.04 and $0.46 \mathrm{~V}$ ( $v s$. SCE) in a $1 \mathrm{M} \mathrm{KOH}$ electrolyte are shown in Fig. 4a. The composite exhibited two redox peaks at about $0.1 / 0.08 \mathrm{~V}$ and $0.4 / 0.33 \mathrm{~V}$ (vs. SCE). The possible reversible redox reactions have been presented as follows: ${ }^{23}$

$$
\begin{gathered}
\mathrm{Cr}_{2} \mathrm{O}_{3}+2 \mathrm{OH}^{-}+\mathrm{H}_{2} \mathrm{O} \leftrightarrow 2 \mathrm{CrO}(\mathrm{OH})_{2}+\mathrm{e}^{-} \\
\mathrm{CrO}(\mathrm{OH})_{2}+\mathrm{OH}^{-} \leftrightarrow \mathrm{CrO}(\mathrm{OH})_{3}+\mathrm{e}^{-}
\end{gathered}
$$

Moreover, larger area of the $\mathrm{Cr}_{2} \mathrm{O}_{3}$ /MWCNT composite indicated that the composite had a higher capacitance than $\mathrm{Cr}_{2} \mathrm{O}_{3}$, which was due to the incorporation of the MWCNT. This can improve the conductivity and the rate of ion transport. Another important reason can be owed to smaller size of the $\mathrm{Cr}_{2} \mathrm{O}_{3}$ nanoparticles, which can provide more active sites during the reaction process as well as shorten the distance for ion diffusion.

As shown in the CV curves of the two samples at various scan rates (Fig. $4 \mathrm{~b}$ and c), compared with those of virginal $\mathrm{Cr}_{2} \mathrm{O}_{3}$, the peak positions of the composite shifted a little because of their different crystal orientation. As for the composites, the location of the redox peaks slightly changed with the increasing scan rate, indicating good reversibility of the redox reactions.
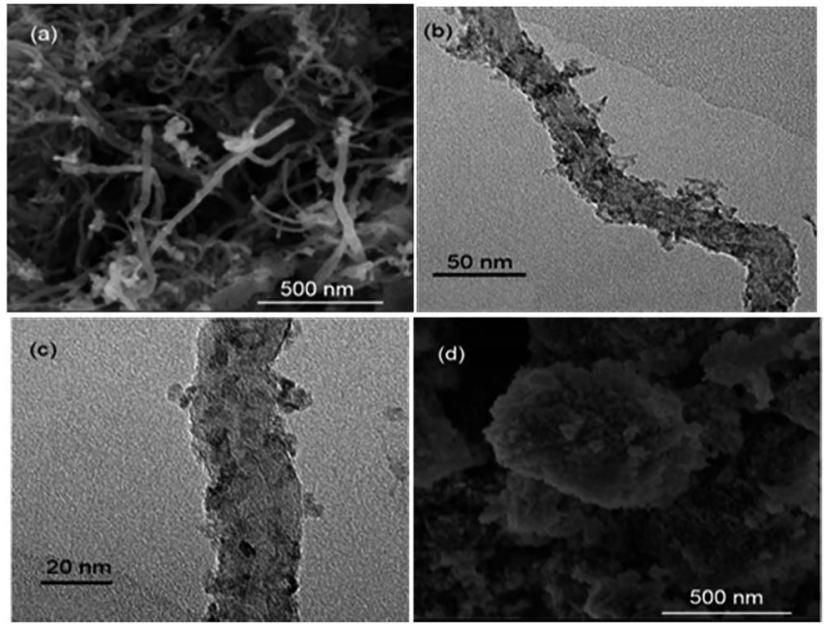

Fig. 3 Morphology of the samples: SEM image (a) and TEM images (b and c) of $\mathrm{Cr}_{2} \mathrm{O}_{3} /$ MWCNTs composite; SEM image of $\mathrm{Cr}_{2} \mathrm{O}_{3}(\mathrm{~d})$. 

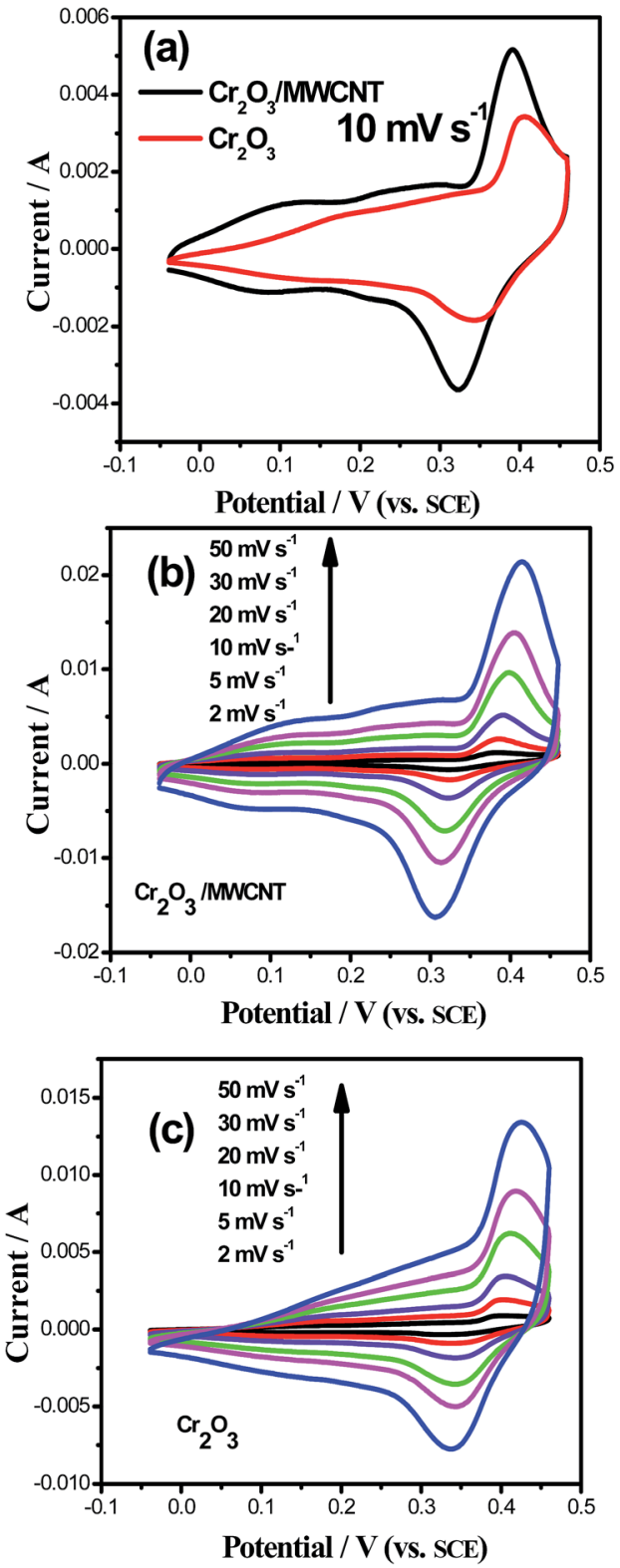

Fig. $4 \mathrm{CV}$ curves of (a) $\mathrm{Cr}_{2} \mathrm{O}_{3}$ and $\mathrm{Cr}_{2} \mathrm{O}_{3}$ /MWCNT composite at the scan rate of $10 \mathrm{mV} \mathrm{s}^{-1}$, (b) $\mathrm{Cr}_{2} \mathrm{O}_{3}$, and (c) $\mathrm{Cr}_{2} \mathrm{O}_{3} / \mathrm{MWCNT}$ composite at various scan rates.

As shown in the GCD curves of the two samples (Fig. 5a), a discharge flat voltage at around $0.3 \mathrm{~V}$ was observed for both samples, which corresponds well to the CV results, indicating a typical pseudocapacitve property of $\mathrm{Cr}_{2} \mathrm{O}_{3}$. Note that the $\mathrm{Cr}_{2} \mathrm{O}_{3} / \mathrm{MWCNT}$ composite has much longer discharge time than $\mathrm{Cr}_{2} \mathrm{O}_{3}$, confirming its higher specific capacitance. The GCD curves of the $\mathrm{Cr}_{2} \mathrm{O}_{3}$ /MWCNT composites at various current densities are shown in Fig. 5b. The calculated specific capacitance values were $257,189,164$, and $153 \mathrm{~F} \mathrm{~g}^{-1}$, at $0.25,0.5,1$, and $1.5 \mathrm{~A} \mathrm{~g}^{-1}$, respectively. Even at the high current density of 2 $\mathrm{A} \mathrm{g}^{-1}$, the composite possessed a high specific capacitance of $138 \mathrm{~F} \mathrm{~g}^{-1}$. However, the capacitance value of virginal $\mathrm{Cr}_{2} \mathrm{O}_{3}$ was only $42 \mathrm{~F} \mathrm{~g}^{-1}$ (Fig. 5c). The cycling stability of both the electrodes were evaluated using GCD at $0.5 \mathrm{~A} \mathrm{~g}^{-1}$ (Fig. 5d).
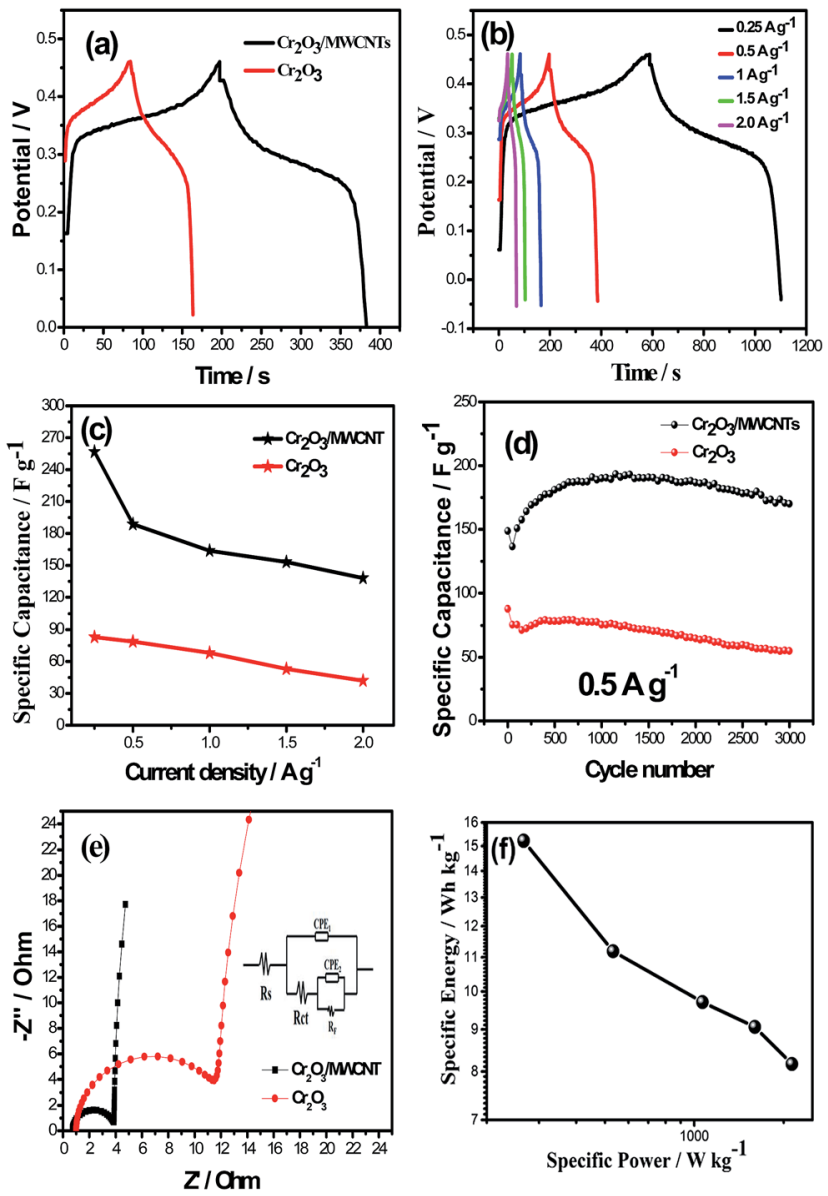

Fig. 5 Electrochemical characteristics of the materials: (a) GCD curves of the two samples at $0.5 \mathrm{~A} \mathrm{~g}^{-1}$, (b) GCD curves of the $\mathrm{Cr}_{2} \mathrm{O}_{3} /$ MWCNT composite at various current densities, (c) specific capacitance of the two materials vs. current densities, (d) cycling performance of the two samples at $0.5 \mathrm{~A} \mathrm{~g}^{-1}$, and (e) EIS curve of the two samples at the frequency of $0.1 \mathrm{~Hz}$ and equivalent circuit used for fitting the impedance spectra. (f) Ragone plot related to energy and power densities of the $\mathrm{Cr}_{2} \mathrm{O}_{3} / \mathrm{MWCNT} / /$ AC ASC.

Obviously, at the beginning of the cycling, the specific capacitance gradually increased due to an initial activation process. ${ }^{24}$ After 3000 cycles, the capacity fade of the $\mathrm{Cr}_{2} \mathrm{O}_{3}$ /MWCNT composite and virginal $\mathrm{Cr}_{2} \mathrm{O}_{3}$ were $12 \%$ and $38 \%$ of their highest capacitance, respectively. These values are superior to those reported in the literature. ${ }^{23,25}$ Moreover, there was a remarkable increase in the specific capacitance due to the introduction of the MWCNTs. Specifically, at the constant stage, the composite electrode possessed a high specific capacitance of $180 \mathrm{~F} \mathrm{~g}^{-1}$, nearly $110 \mathrm{~F} \mathrm{~g}^{-1}$ higher than that of the virginal $\mathrm{Cr}_{2} \mathrm{O}_{3}$ electrode. The good cycling stability and high pseudocapacitance of the composite can be explained as follows: ${ }^{9}$ the MWCNTs can form an interconnected conductive network, which can increase the conductivity.

The EIS curves of both the samples are shown in Fig. 5e. The amplitude of the perturbation was $5 \mathrm{mV}$ and the data were obtained in the frequency range from $0.01 \mathrm{~Hz}$ to $10 \mathrm{kHz}$. The equivalent circuit used for fitting the impedance spectra is 
presented in the inset of Fig. 5e, which consists of the bulk solution resistance $R_{\mathrm{s}}$, charge transfer resistance $R_{\mathrm{ct}}$, pseudocapacitive element $R_{\mathrm{f}}$, and constant phase element (CPE). ${ }^{26}$ The semicircle in the high frequency region resulted from $R_{\mathrm{ct}} \cdot{ }^{9,27}$ The $R_{\text {ct }}$ was estimated to be $3.3 \Omega$ for the $\mathrm{Cr}_{2} \mathrm{O}_{3} / \mathrm{MWCNT}$ composite, which was lower than $11 \Omega$ for virginal $\mathrm{Cr}_{2} \mathrm{O}_{3}$. This result suggests that the reversible reactions on the electrode surface of the $\mathrm{Cr}_{2} \mathrm{O}_{3}$ /MWCNT composite are much facile than those of virginal $\mathrm{Cr}_{2} \mathrm{O}_{3} \cdot{ }^{28}$ Moreover, the intercept on $Z^{\prime}$ indicates $R_{\mathrm{S}}$. Clearly, it was evident that $R_{\mathrm{S}}$ of the composite $(0.7 \Omega)$ was smaller than that of virginal $\mathrm{Cr}_{2} \mathrm{O}_{3}(1.0 \Omega)$, which means that the incorporation of the MWCNTs can decrease the $R_{\mathrm{S}}$ of the composite and that was similar to the actions of CNTs in other composites such as with $\mathrm{MnO}_{2}$ and $\mathrm{V}_{2} \mathrm{O}_{5} \cdot{ }^{29}$ These results can justify the abovementioned results indicating that the incorporation of MWCNTs remarkably enhanced the electrochemical performance of the $\mathrm{Cr}_{2} \mathrm{O}_{3} /$ MWCNT composite.

The applicability of the composite was investigated in an ASC $\left(\mathrm{Cr}_{2} \mathrm{O}_{3} / \mathrm{MWCNTs} / / \mathrm{AC}\right)$, in which the composite/Ni grid acted as a positive electrode and AC (mixed with 10\% PTFE)/Ni grid acted as the negative electrode. The electrochemical measurement was carried out in a $1 \mathrm{M} \mathrm{KOH}$ electrolyte, and the potential ranged from 0 to $1.46 \mathrm{~V}$. The energy and power densities of the ASC systems were calculated according to the following equations:

$$
\begin{gathered}
E=C_{\mathrm{s}}(\Delta V)^{2} / 7.2 \\
P=3600 E / \Delta t
\end{gathered}
$$

where $E\left(\mathrm{~W} \mathrm{~h} \mathrm{~kg}^{-1}\right)$ is the specific energy density, $P\left(\mathrm{~W} \mathrm{~kg}^{-1}\right)$ is the specific power density, $C_{\mathrm{s}}\left(\mathrm{F} \mathrm{g}^{-1}\right)$ is the specific capacitance of the total ASC system, $\Delta V(\mathrm{~V})$ is the potential range, and $\Delta t(\mathrm{~s})$ is the discharge time.

Fig. $5 \mathrm{f}$ shows the Ragone plot related to the energy and power densities of the $\mathrm{Cr}_{2} \mathrm{O}_{3}$ /MWCNTs//AC ASC. At the power density of $266 \mathrm{~W} \mathrm{~kg}^{-1}$, its energy density can reach up to $15.2 \mathrm{~W} \mathrm{~h} \mathrm{~kg}^{-1}$; even at the high power density of $2130 \mathrm{~W} \mathrm{~kg}^{-1}$, the energy density could still remain $8.17 \mathrm{~W} \mathrm{~h} \mathrm{~kg}^{-1}$.

The outstanding electrochemical performance of the composite can be attributed to the following reasons: (1) MWCNTs provide a framework for the $\mathrm{Cr}_{2} \mathrm{O}_{3}$ nanoparticles and can prevent their agglomeration, which enable the nanoparticles to retain high specific surface area, thereby shortening the diffusion distance during the charge-discharge progress; (2) MWCNTs provide good conductivity; thus, the composite has fast electron transfer rate and low charge transfer resistance, which may accelerate the kinetic process in the redox reaction; (3) MWCNTs have excellent mechanical properties and good chemical and thermal stability, which provide a matrix for long term cycling stability; and (4) another reason is perhaps the preferred crystal orientation due to the MWCNTs template. ${ }^{\mathbf{1 6 , 3 0}}$

\section{Conclusion}

In summary, a composite of $\mathrm{Cr}_{2} \mathrm{O}_{3}$ with MWCNTs was successfully synthesized. The diameter of the $\mathrm{Cr}_{2} \mathrm{O}_{3}$ nanoparticles was only several nanometers, and these nanoparticles were strongly anchored on the MWCNTs. The specific capacitance of the composite was $257 \mathrm{~F} \mathrm{~g}^{-1}$ at the current density of $0.25 \mathrm{~A} \mathrm{~g}^{-1}$. The composite also exhibited excellent cycling stability with the capacity fade of $12 \%$ after 3000 cycles. Moreover, the energy density of the $\mathrm{Cr}_{2} \mathrm{O}_{3} / \mathrm{MWCNTs} /$ AC ASC could reach up to $15.2 \mathrm{~W} \mathrm{~h} \mathrm{~kg}^{-1}$ (at $266 \mathrm{~W} \mathrm{~kg}^{-1}$ ). The outstanding electrochemical performance of the composite can be ascribed to good conductivity of the MWCNTs, high specific surface area of the composite, and preferred orientation of the crystal planes. Therefore, the $\mathrm{Cr}_{2} \mathrm{O}_{3}$ /MWCNT composite can be applied as a potential electrode material for aqueous supercapacitor. This study also provides a strong basis to exploit the Cr-based composite for supercapacitors.

\section{Acknowledgements}

Financial support received from the National Materials Genome Project (2016YFB0700600), China National Distinguished Youth Scientists (51425301), NSFC (U1601214), and Sanyo Chemical Co. Ltd., Japan, is greatly appreciated.

\section{Notes and references}

1 A. S. Arico, P. Bruce, B. Scrosati, J. M. Scrosati and W. V. Schalkwijk, Nat. Mater., 2005, 4, 366-377.

2 J. Hassoun, F. Bonaccorso, M. Agostini, M. Angelucci, M. G. Betti, R. Cingolani, M. Gemmi, C. Mariani, S. Panero, V. Pellegrini and B. Scrosati, Nano Lett., 2014, 14, 4901-4906.

3 F. Li, G. Li, H. Chen, J. Q. Jia, F. Dong, Y. B. Hu, Z. G. Shang and Y. X. Zhang, J. Power Sources, 2015, 296, 86-91.

4 J. L. Zhang, G. L. Chen, Q. Zhang, F. Kang and B. You, ACS Appl. Mater. Interfaces, 2015, 7, 12760-12766.

5 L. L. Zhang and X. S. Zhao, Chem. Soc. Rev., 2009, 38, 25202531.

6 M. J. Zhi, C. C. Xiang, J. T. Li, M. Li and N. Q. Wu, Nanoscale, 2013, 5, 72-88.

7 S. Bose, T. Kuila, A. K. Mishra, R. Rajasekar, N. H. Kim and J. H. Lee, J. Mater. Chem. A, 2012, 22, 767-784.

8 J. G. Wang, F. Y. Kang and B. Q. We, Prog. Mater. Sci., 2015, 74, 51-124.

9 Q. T. Qu, P. Zhang, B. Wang, Y. H. Chen, S. Tian, Y. P. Wu and R. Holze, J. Phys. Chem. C, 2009, 113, 14020-14027.

10 W. Tang, Y. Y. Hou, X. J. Wang, Y. Bai, Y. S. Zhu, H. Sun, Y. B. Yue, Y. P. Wu, K. Zhu and R. Holze, J. Power Sources, 2012, 197, 330-333.

11 F. Yang, L. B. Zhang, A. Zuzuarregui, K. Gregorczyk, L. Li, M. Beltran, C. Tollan, J. Brede, C. Rogero, A. Chuvilin and M. Knez, ACS Appl. Mater. Interfaces, 2015, 7, 20513-20519.

12 Q. T. Qu, Y. Shi, L. L. Li, W. L. Guo, Y. P. Wu, H. P. Zhang, S. Y. Guan and R. Holze, Electrochem. Commun., 2009, 11, 1325-1328.

13 Y. J. Wu, G. H. Gao, H. Y. Yang, W. C. Bi, X. Liang, Y. R. Zhang, G. Y. Zhang and G. M. Wu, J. Mater. Chem. A, 2015, 3, 15692-15699. 
14 W. Tang, L. L. Liu, S. Tian, L. Li, Y. B. Yue, Y. P. Wu and K. Zhu, Chem. Commun., 2011, 47, 10058-10060.

15 Y. Liu, B. H. Zhang, Y. Q. Yang, Z. Chang, Z. B. Wen and Y. P. Wu, J. Mater. Chem. A, 2013, 1, 13582-13587.

16 X. W. Wang, M. X. Li, Z. Chang, Y. Q. Yang, Y. P. Wu and X. Liu, ACS Appl. Mater. Interfaces, 2015, 7, 2280-2285.

17 K. Y. Tao, P. Y. Li, L. T. Kang, X. R. Li, Q. F. Zhou, L. Dong and W. Liang, J. Power Sources, 2015, 293, 23-32.

18 W. Chen, Z. L. Fan, L. Gu, X. H. Bao and C. L. Wang, Chem. Commun., 2010, 46, 3905-3907.

19 S. Lei, X. Peng, Z. Liang, X. Li, C. Wang, B. Cheng, Y. Xiao and L. Zhou, J. Mater. Chem., 2012, 22, 1643-1651.

20 W. Tang, Y. Y. Hou, F. X. Wang, L. L. Liu, Y. P. Wu and K. Zhu, Nano Lett., 2013, 13, 2036-2040.

21 Z. N. Yu, L. Tetard, L. Zhai and J. Y. Thomas, Energy Environ. Sci., 2015, 8, 702-730.

22 J. Zhi, Y. F. Wang, S. Deng and A. Hu, RSC Adv., 2014, 4, 40296-40300.
23 C. Y. Cummings, G. A. Attard, J. M. Mitchels and F. Marken, Aust. J. Chem., 2012, 65, 65-71.

24 R. B. Rakhi, W. Chen, D. Cha and H. N. Alshareef, Nano Lett., 2012, 12, 2559-2567.

25 X. Y. Xu, J. Z. Wu, N. A. Yang, H. Na, L. Z. Li and J. P. Gao, Mater. Lett., 2015, 142, 172-175.

26 Y. Liu, Z. B. Wen, X. W. Wu, X. W. Wang, Y. P. Wu and R. Holze, Chem. Commun., 2014, 50, 13714-13717.

27 L. J. Wang, K. Zhang, Z. Hu, W. C. Duan, F. Y. Cheng and J. Chen, Nano Res., 2013, 7, 199-208.

28 L. B. Ma, H. Zhou, X. P. Shen, Q. R. Chen, G. X. Zhu and Z. Y. Ji, RSC Adv., 2014, 4, 53180-53187.

29 W. Tang, X. W. Gao, Y. S. Zhu, Y. B. Yue, Y. Shi, Y. P. Wu and K. Zhu, J. Mater. Chem., 2012, 22, 20143-20145.

30 F. X. Wang, X. W. Wang, Z. Chang, Y. S. Zhu, L. J. Fu, X. Liu and Y. P. Wu, Nanoscale Horiz., 2016, 1(1), 272-289. 